\title{
RESISTIR PARA RE (EXISTIR): REFLEXÕES SOBRE A PRODUÇÃO DE RESISTÊNCIAS POR ESTUDANTES GAYS NA ESCOLA DE ENSINO MÉDIO
}

\author{
RESIST TO RE (EXIST): REFLECTIONS ON THE PRODUCTION OF RESISTANCE \\ BY GAY STUDENTS AT HIGH SCHOOL
}

JAIME PEIXOTO 1

1 Universidade Federal de Minas Gerais, doutorando no Programa de Pós Graduação em Educação
FAE/UFMG. Brasil. E-mail: jaimepeixotoufmg@gmail.com

\author{
ART ICLE INFO \\ Article history: \\ Received 2020-05-07 \\ Accepted 2020-06-20 \\ Available online 2020-06-20
}

Palavras-chave: Resistência. Jovens gays. Escola.

Conservadorismo.

Keywords: Resistance. Young gays. School. Conservatism.

RESUMO. Este artigo, fruto dos resultados de uma pesquisa de mestrado em educação, questiona por quais meios jovens gays produzem resistências e enfrentamentos às práticas comumente nomeadas como homofóbicas no espaço escolar. De que maneiras tais jovens estariam produzindo resistências ao conservadorismo de gênero e sexualidade no campo da educação? Tendo como embasamento a perspectiva pós-crítica, utilizo do pensamento de autores como Michel Foucault para evidenciar os processos de criação de estratégias de resistências, escapes e deslocamentos empreendidos pelos participantes da pesquisa. Tendo em mente a já constatada realidade de que jovens gays são vítimas de homofobia nas escolas e, principalmente, o atual contexto político conservador e reacionário de nosso país, busca-se, neste artigo, evidenciar outro lado do debate, a saber, as resistências que tais sujeitos engendram dentro das relações de forças envolvendo a vivência transgressora do gênero e da sexualidade no meio escolar em tempos de conservadorismos. Para tanto, utilizou-se da técnica da Entrevista Narrativa On Line (JANE FÉLIX, 2010) para produzir as informações desta pesquisa com um grupo de 06 jovens de diferentes cidades brasileiras. Como resultados, destaco a criação e operacionalização pelos sujeitos da pesquisa das técnicas do "deslocamento do discurso agressor" e do "ignorar como forma de fazer frente ao conservadorismo de gênero e sexualidade no campo escolar, ao mesmo tempo em que produzem para si uma ética positivada e empoderada de seu gênero e sua sexualidade.

\begin{abstract}
This article, the result of the results of a master's research in education, asks by what means young gay people produce resistance and confrontation to practices commonly referred to as homophobic in the school space. In what ways are these young people producing resistance to gender and sexuality conservatism in the field of education? Based on the post-critical perspective, I use the thoughts of authors like Michel Foucault to highlight the processes of creating strategies for resistance, escapes and displacements undertaken by the research participants. Bearing in mind the already verified reality that young gays are victims of homophobia in schools and, mainly, the current conservative and reactionary political context of our country, this article seeks to highlight another side of the debate, namely, the resistance that such subjects engender within the power relations involving the transgressive experience of gender and sexuality in the school environment in times of conservatism. For this, we used the technique of Narrative Interview On Line (JANE FÉLIX, 2010) to produce the information of this research with a group of 06 young people from different Brazilian cities. As a result, I highlight the creation and operationalization by the research subjects of the techniques of "displacement of the aggressor discourse" and of "ignoring as a way to face the conservatism of gender and sexuality in the school field, at the same time that they produce for themselves an ethics positive and empowered of their gender and sexuality.
\end{abstract}




\section{INTRODUÇÃO}

Os estudos sobre as ditas "minorias sexuais" na escola são realizados, em parte, na perspectiva dos estudos sobre Homofobia. O termo homofobia, usado pela primeira vez pelo psicólogo clínico George Weinberg (1972), foi cunhado para nomear o "medo de estar próximos a homossexuais". Entretanto, com o passar dos anos seu sentido foi ampliado passando a englobar "uma variada gama de sentimentos e atitudes negativas em relação a homossexuais e à homossexualidade" (JUNQUEIRA, 2009; RIOS, 2009). Como resultado da ampliação semântica do termo, surgiram inúmeras subclassificações nas quais a homofobia pode ser discutida, conforme nos mostra Daniel Borrilo (2000).

Assim, homofobia, geralmente, é a primeira palavra que vem em nossa mente quando, por exemplo, pensamos em Homossexualidades nas escolas. No entanto, que tipo de aluno gay é evidenciado nessa literatura? Como jovens gays vem sendo percebidos pelos trabalhos sobre sexualidade (homossexualidade) na educação?

\section{FUNDAMENTAÇÃO}

Registra-se que dos anos 2000 para cá muitas pesquisas foram financiadas com o fim de identificar a ocorrência e a dimensão de tais práticas homofóbicas nas escolas brasileiras para, a partir daí, pensar na elaboração de políticas de combate à discriminação de alunos LGBTT. Entre estes, se pode mencionar os estudos de Abramovay, 2004; Borges e Meyer, 2008; Junqueira, 2009; Brasil, 2009. Tais pesquisas revelaram um preocupante quadro de intolerância às identidades sexuais que não conformam com o padrão heteronormativo, sendo "descritas como desviantes e anormais" (BRITZMAN, 1996). Notase que o empenho de tais pesquisa está em expor, denunciar os casos de discriminação sofridos pelos alunos "desviantes", explicitando o caráter arbitrário que a heterossexualização do espaço escolar e das práticas pedagógicas possuem, buscando retirar tais sujeitos da subalternização e da invisibilidade (LOPES, 2009).

Explicito que, diferente do que se tem produzido sobre homofobia na escola e jovens gays vítimas de discriminação no campo escolar (BONTEMPO, 2002; DAVI, 2005; JUNQUEIRA, 2007), não é minha intenção evidenciar e traçar um perfil de um aluno vitimizado pela homofobia, passivo diante dos jogos de poder dentro da escola, que sendo alvo da dita discriminação homofóbica se cala e se invisibiliza. Busco outro lado da questão, talvez ainda obscuro e, por isso, instigante, mostrar um aluno que, embora seja alvo de 
inúmeros preconceitos, consegue inserir-se e firmar-se nas teias de conflito de modo a conseguir produzir efeitos, resistências, já que, como diz Jesus Generelo Lanaspa (2009), os jovens são conscientes de sua invisibilidade e do que isto representa, querem rompe-la, querem ser escutados e entendidos.

$\mathrm{Na}$ literatura especializada tais sujeitos são retratados, muitas vezes, numa posição de desvantagem, sendo vítimas inertes, na maioria das vezes, de discursos e práticas de agressão e discriminação, tendendo sempre ao isolamento, a invisibilização e ao silêncio (LIONÇO E DINIZ, 2009; FONTES, 2009; BORGES E MEYER, 2008; GALÀN, 2009; LANASPA, 2009; PEREIRA E LEAL, 2002, FERRARI, 2011, 2008). E de fato, o são! Sim, milhões de jovens ainda hoje são vítimas de homofobia nas escolas do Brasil conforme mostra pesquisa feita pela fundação Perseu Abramo (2011).

De fato, não estou aqui desmerecendo os trabalhos produzidos. Uma gama considerável de excelentes produções acadêmicas sobre o tema trouxe inegáveis contribuições ao debate na atualidade (COSTA E JOCA, 2011; JÚNIOR, 2010; LONGARAY, 2010; NARDI, 2013; CARVALHO E LUZ, 2011, FERRARI, 2010; JUNQUEIRA, 2009). O que defendo aqui, não é que esqueçamos que a homofobia faz vítimas, mas que atentemos também para o fato de que existem indivíduos que, fazendo uso dos códigos do meio onde estão inseridos conseguem dar visibilidade a suas posturas, seus discursos, suas maneiras de se relacionar, se despindo das vestes de mera vítima e se armando para entrar no jogo das negociações na escola.

Por exemplo, é recorrente na literatura anteriormente citada expressões como "sujeitos abjetos", "desumanos", "sem voz", "inferiorizados", "reprimidos", entre outras adjetivações que, denunciam uma realidade que está posta, mas, por outro lado, reforçam a ideia de que tais alunos possuem pouco ou nenhuma capacidade de empoderamento.

O convite que faço é o de pensarmos outras possibilidades. Pois como nos desafia Judith Halberstam (2012) não deveríamos buscar romper - eu diria superar- certas narrativas que tendem a alocar o sujeito homossexual como "eterna vítima"? Onde estão aqueles sujeitos que, mesmo sofrendo com o baque do "choque" entre os discursos concorrentes sobre sexualidade, conseguem produzir resistências, acarretando em efeitos para o meio escolar? Invés de somente pensarmos como a escola "desmantela" o jovem gay enquanto sujeito possuidor de uma subjetividade legítima, que tal pensarmos, em contrapartida, em como tais alunos homossexuais "desmantelam" o espaço escolar e resistem? 


\section{METODOLOGIA}

Os sujeitos entrevistados foram selecionados por indicação. Através do Facebook, estabeleci contato com alguns conhecidos que, por sua vez, me apresentaram virtualmente a alguns jovens gays de diferentes estados do país. Foram contatados 10 jovens gays do sexo masculino. Embora tenhamos tentado contatar jovens maiores de idade que estivessem cursando o ensino médio, a grande maioria dos que aceitaram participar da pesquisa (9 sujeitos), já havia concluído sua formação básica nos anos anteriores. Dos 10 jovens entrevistados, 9 estudaram em escolas públicas. Dois deles cursam o ensino superior em instituições públicas de ensino, os demais já estão inseridos no mercado de trabalho e dizem ter planos de cursar um curso de nível superior.

Em seguida, iniciei uma primeira conversa com os participantes, afim de me apresentar, falar um pouco mais sobre como funcionaria a pesquisa e, combinar um horário conveniente para que as entrevistas fossem iniciadas. Destacava, principalmente, que seriam realizadas virtualmente através da rede social Facebook. Flick (2009) nos chama atenção para o fato de que

uma precondição para o sucesso na condução da entrevista é explicar o caráter específico da situação de entrevista ao entrevistado. Para este propósito, sugere-se que se dê uma atenção especial à explicação, em detalhes, dos objetivos e dos procedimentos durante a fase de recrutamento de entrevistados (FLICK, 2009, p. 170).

As entrevistas que compõem o corpus deste trabalho foram realizadas dos meses de julho à outubro de 2015. É importante que se diga que as entrevistas não foram feitas numa única ocasião. Foram precisos alguns encontros virtuais para concluir algumas delas, isso porque muitos participantes se ausentavam das redes, não retornavam contato ou não estavam on-line no horário marcado, fazendo com que fosse preciso remarcar muitas das entrevistas, prolongando o período de feitura das mesmas. Seguindo os moldes de Flick (2009), realizamos entrevistas on-line de forma Síncrona, ou seja, conversamos em tempo real com os participantes.

Para a realização das Entrevistas Narrativas On-line foi elaborado um roteiro de entrevistas. Este me oferecia um "cardápio de perguntas", expressão utilizada por Jeane Félix (2012), que poderiam ser usadas durante as entrevistas. No entanto, destaco que em algumas situações fez-se necessário deixar o roteiro um pouco de lado, para explorar melhor determinados elementos que os entrevistados me traziam. Procurou-se com a sistematização do material coletado traçar um panorama das experiências relatadas pelos jovens participantes, buscando evidenciar de que formas os entrevistados produziram enfrentamentos, resistindo às discriminações que ocorrem no espaço escolar. 


\section{DISCUSSÃO E RESULTADOS}

\section{A PRODUÇÃO DE RESISTÊNCIAS NO CONTEXTO DA PESQUISA}

\section{. Estratégia 1: o deslocamento do discurso agressor}

Um primeiro movimento identificado como uma estratégia que visa resistir às situações de discriminação foi nomeado por mim de "deslocamento do discurso agressor". O que isto, de fato, significa? Bem, ao discorrer sobre isto estou, na verdade, evidenciando a capacidade que alguns dos jovens entrevistados mostraram de reverter o preconceito contra o agressor, muitas vezes, fazendo um uso positivado de discursos e práticas tidas como pejorativas, como nos mostra Anderson Ferrari (2011) quando comenta que

O discurso considerado homofóbico atua para menosprezar o sujeito que dele é alvo, porém, ele também pode ser entendido e utilizado de outra forma, abrindo uma nova possibilidade. Ao ser chamado por um nome se oferece à pessoa certa possibilidade de existência e resistência. (FERRARI, 2011, p. 76).

A possiblidade de resistir, partindo da utilização desses discursos abre um novo campo de análise. Diferente do que, geralmente, tem sido descrito em algumas pesquisas, foi possível observar que os jovens entrevistados não se contentaram com o status que lhes foi atribuído de meras vítimas do preconceito. Pois, como nos disse um dos entrevistados "não é porque você é gay que você vai se deixar desmoralizar" (Sujeito 8). Neste respeito, foi possível identificar nos relatos dos jovens participantes uma série de situações onde a resistência tomou forma através de um uso ressignificado de discursos e práticas deslegitimadoras. Vejamos a seguinte situação relatada por Lucas

“... um menino lá do fundão gritou: "essa coca é Fanta”. Eu voltei, olhei para o fundo e disse: "é eu sou Fanta mesmo". Daí todo mundo ficou de pé e me aplaudiram. Por mais que eu fosse assumido, nem todos tinham contato comigo, eles achavam que eu tinha medo. Depois disso um monte de gente de outras salas veio me dar os parabéns por falar tão abertamente da minha sexualidade". (Sujeito 1).

Do relato acima, podemos extrair alguns pontos para consideração. Primeiro, fazer uso dessa estratégia pressupõe uma relação direta com a ideia do "assumir-se"1. Isso porque, ao que parece, "assumir-se", ou seja, essa auto positivação que se evidencia através da afirmação do comportamento homossexual, constitui-se na condição primeira, possibilitando que o "deslocamento do discurso agressor" tenha eficiência. Acionar tal estratégia pressupõe uma relação confortável com a própria sexualidade, de modo que, diante de situações de discriminação, invés do discurso pejorativo causar constrangimento

\footnotetext{
1 É importante dizer que no atual contexto conservador de nosso país assumir-se não é algo simples e banal. Pode significar o aumento da precariedade e da insegurança das vidas daqueles e daquelas que se assumem. Aqui, o "assumir-se" será entendido como uma forma de resistência, mas, quero lembrar que, em muitos casos, permanecer no "armário" também pode configurar-se numa estratégia de resistência eficaz e legítima.
} 
ao jovem gay, será utilizado por este como contra-ataque, visando despotencializá-lo nas suas bases.

Segundo, tal estratégia contribui para o rompimento com a ideia de que, nas relações de poder envolvendo a sexualidade na escola, tais jovens estariam em situação de desvantagem, sendo vistos, muitas vezes, como incapazes de produzir mudanças nesta realidade. No entanto, quando o jovem gay, ao ser afrontado, adentra na lógica do agressor e a subverte, na sua essência, na sua base, ele está mostrando a quem interessar que, podem ser igualmente produtores de movimentos ativos dentro das relações de força. Como disse um dos entrevistados, "se comportar como vítima só te fará mais fraco" (Sujeito 2). Com isso, torna-se possível construir um panorama das relações de poder onde tais sujeitos são evidenciados como possuidores de grande "poder de fogo".

Dito isto, voltemos a ideia de contra-ataque que está subentendida no "deslocamento do discurso agressor". Sobre este ponto, Lisete Bampi (2002) comenta que

A resistência "pode inventar novas regras enquanto ocupa um lugar sobre o tabuleiro de xadrez ou desempenhando o jogo adversário". Mas este tipo de invenção requer estratégias: "a arte de pegar emprestado, de imitar, de substituir". Prover uma resposta "é roubar e adequar, novamente, as armas dos adversários, virando-as do avesso como uma luva e oferecê-las de volta". (BAMPI, 2002, p. 143).

Assim, a capacidade que a resistência possui de "virar o jogo contra o adversário", pegando suas armas emprestadas e utilizando-as contra ele, nos lembra que, quando se trata de relações de poder, sempre é possível empreender movimentos inventivos que abalem suas estruturas. Estes podem abarcar, inclusive, estratégias que foram produzidas visando reiterar a lógica do poder vigente, mas que, sob determinadas circunstâncias, podem ser reapropriadas, sendo utilizadas contra o poder, em processos de enfrentamento ativos. Vejamos como isso funciona na prática, ao observar os seguintes relatos

"Depois de um tempo sempre arrumava uma resposta à altura. Se brincavam ou riam da minha cara, eu fazia com que a pessoa que fez isso fosse o motivo da piada. Várias vezes no intervalo, alguém de outra sala vinha falar absurdos pra mim, mas eu apenas ria da cara dele, fazia alguma piada sobre a aparência dele ou sobre a própria situação. Ficava aquela história de quem dá a última risada. Vinham rir de mim, mas acabavam se tornando a própria piada. Várias pessoas me viam como valentão, como se eu praticasse o bullying, quando na verdade só estava me defendendo". (Sujeito 3).

Mais ainda,

"Eu penso que para algumas pessoas a melhor forma de se defender é contra atacar. Brincar com as brincadeiras deles, zombar deles também". (Sujeito 4). 
O que podemos apreender desses relatos? A capacidade de ressignificar as agressões e usá-las como instrumentos de defesa e de ataque pelos jovens gays pesquisados, mostrou-se ser uma eficiente forma de fazer frente às discriminações. Isso porque, para além da inviabilização do potencial deslegitimador presente nas chacotas e "brincadeiras" temos, também, o que parece ser uma tomada de consciência por parte desses jovens de que podem, utilizando das mesmas táticas dos agressores, fazê-los, mesmo que por um momento, experimentar o gosto de ser oprimido. Essa mudança nos papéis costumeiramente performados no espaço escolar, deixa evidente o alto grau de empoderamento que tal estratégia, atrelada ao "assumir-se" pode atribuir ao sujeito que dela faz uso.

Não podemos esquecer que, o "deslocamento do discurso agressor" configura-se num movimento que sinaliza, dentro do jogo de poder presente na escola, para a possibilidade de mudanças na hierarquia do poder. Todavia, seria o caso de apontar para a necessidade de uma supremacia do comportamento homossexual em relação à heterossexualidade? Seria esta a solução para as relações discriminatórias que ocorrem na escola, colocar o oprimido no lugar do opressor? Estou inclinado à acreditar que não! Embora Foucault nos lembre que "a resistência sempre toma apoio na situação que ela combate" (DE II, p. 1560), uma simples inversão de papéis não seria suficiente para transformar a realidade desigual que perpassa as relações envolvendo a sexualidade no contexto da escola de ensino médio. Talvez, seja o caso de reconhecermos que, mais importante do que inverter tais papéis, seria descobrir como produzir tais enfrentamentos e mudanças nas relações de poder sem, necessariamente, reproduzir e perpetuar a lógica deslegitimadora referente aos comportamentos sexuais.

Pode-se observar que, no caso dos jovens pesquisados, a prontidão e disposição em reagir aos enfrentamentos, gera efeitos não só no aluno gay. Estas transformam, inclusive, a forma pela qual o agressor se posiciona nas situações de discriminações. Observemos o que nos foi relatado por Lucas

"Não me calava, eu encarava eles. Nunca baixei a cabeça. Quando eles furavam a minha fila da merenda me chamando de "viadinho", eu dizia bem alto: "lá vem eles virando esse "rabão" (Bundão) para mim, só querem entrar na minha frente para isso. Eles tinham medo de me humilhar porque eu sempre tinha resposta pra eles". (Sujeito 1).

Pensar tal disposição ao enfrentamento é reconhecer que o que está em jogo é a superação da imagem despotencializada que, por muito tempo, foi atribuída a tais jovens no contexto da escola de ensino médio. Neste ínterim, o "deslocamento do discurso agressor" tem um duplo caráter, por um lado, evidencia uma vivência empoderada da sexualidade, e, por outro, denuncia a fragilidade do discurso agressor, mostrando que, a heterossexualidade pode ser tão vítima dos discursos deslegitimadores quanto a homossexualidade, e que isto 
pode ser feito revertendo a lógica da discriminação e questionando as bases do entendimento da heterossexualidade como único comportamento legítimo.

Atrelado a esta questão está o desejo, por parte do jovem gay, de vivenciar a sexualidade de forma segura, sem uma preocupação exacerbada com as expectativas dos outros, como vemos no seguinte relato

"Cabeça erguida, sorrisão no rosto e consciência de que gay, mulherzinha ou qualquer outro termo pejorativo não são ofensas pra quem é seguro consigo mesmo. A partir do momento que deixo o outro interferir na minha felicidade eu me vitimizo". (Sujeito 1).

Entendo, assim, que, no final das contas, ao utilizar o "deslocamento do discurso agressor" como instrumentos de resistência, o que está em jogo não é somente desestabilizar as relações de poder, mas, principalmente, lutar pela criação de possibilidades de vivências outras da sexualidade, que não sejam constrangidas pela lógica repressora do poder que delegou à heterossexualidade o status de único comportamento legítimo. Assim, fica nítido que tal estratégia tem desdobramentos subjetivos nos sujeitos, bem como nas formas como são construídas as relações de poder referentes à sexualidade dos sujeitos no campo escolar.

Entretanto, esta não foi a estratégia mais recorrente nas falas do entrevistados. Identifiquei um ponto que, ao que parece, configura-se na estratégia mais utilizada pelos jovens entrevistados.

\section{Estratégia 2: 0 “ignorar”}

Das estratégias identificadas nos relatos dos jovens pesquisados, houve uma que foi mais recorrente entre os participantes. Esta se refere a capacidade de "ignorar" as chacotas, piadas e "brincadeiras" de cunho pejorativo, como vemos nos seguintes relatos: "eu ignorava sempre" (Sujeito 5), "eu realmente não ligava, eu ria na cada deles e dizia: é só isso?" (Sujeito 1), "eu não ligo pra ideia contrárias, não me importo" (Sujeito 5), "não ligar para quem tenta te atingir, para o que os outros pensam" (Sujeito 6).

Diante de uma situação de discriminação, parece que os jovens desenvolveram a habilidade de se recusar a dar validade ao discurso do agressor, desconsiderando-o, fazendo pouco caso dele, demonstrando que o discurso proferido tem pouco ou nenhum efeito sobre a forma como eles se veem e vivenciam a sua sexualidade, como nos relatou Lucas

"Quando eles me confrontavam eu não recuava. Eu ria na cara deles e dizia: é só isso? Tá, agora deixa eu ir aqui cuidar da minha vida". (Sujeito 1).

Essa espécie de blindagem subjetiva pressupõe o entendimento, por parte do jovem gay, de que sua sexualidade não se configura numa existência ilegítima. Além disso, considera o discurso do agressor aviltante. Defendem-se caracterizando o agressor como 
ignorante, ultrapassado, etc., na tentativa de interditar seus efeitos denegridores. Observemos o que os entrevistados comentaram sobre isso

"Eu achava a melhor forma de me defender. Tipo a pessoa me jogava uma piada, uma "chacota", eu apenas fingia que não era comigo ou, então, não dava a mínima bola. Na maioria dos casos a pessoa se tocava que as

E também, piadas não estavam funcionando mais". (Sujeito 5).

"O fato de uma pessoa ser ignorante significa que ela está fechada para os conhecimentos. Quando uma pessoas ignorante me discrimina eu desprezo. Mostro que, diferente dela, sou uma pessoa evoluída, desapegada de idiotice e independente. Não me deixo levar por qualquer devaneio de uma pessoa Neandertal mentalmente". (Sujeito 7).

Vemos nos relatos acima uma evidente disposição em não dar ao discurso agressor demasiada atenção ou importância. Assim, a decisão tomada pelos jovens foi a de desconsiderá-lo, não porque não cause incômodo, mas, porque parecem ter assimilado a ideia de que, na realidade, são tais comportamentos agressores e discriminatórios que deslegitimam os sujeitos que dele fazem uso. Ocorre, assim, um deslocamento no jogo de forças vigente, já que tais jovens, por fazerem frente às hostilidades que lhe são direcionadas, acabam por reconfigurar o lugar da abjeção. Esta, agora, na lógica aqui analisada, representaria o agressor que sustenta e faz circular um discurso "ignorante", "atrasado", "não evoluído" e, não mais o comportamento homossexual.

Entender o "ignorar" como uma estratégia ativa de resistência, significa concebê-lo como uma forma de recusa ao desconfortável lugar reservado às homossexualidades. Mais ainda, significa que o potencial que um discurso pode ter de interpelar corpos e subjetividades, neste caso, os discursos considerados homofóbicos direcionados ao corpo homossexual, depende do quanto o sujeito que dele é alvo tem positivado em si, no seu interior, a homossexualidade como um comportamento favorável, como nos disse Lucas "quando eu me mostro feliz sendo como sou, as pessoas veem que eu brilho, coisas ruins não nos fazem sorrir. O preconceito é uma coisa ruim, nós não".

Assim, o "ignorar" não se trata apenas de "fingir que o assunto não é comigo". Esta estratégia se aproxima da "dissimulação honesta" elaborada por Torquatto Accetto (2001) e discutida por Marlucy e Sanches (2020) que se refere a prática de camuflar o que se quer e o que se sente, silenciar ou omitir algo com honestidade. Trata-se de uma ação calculada. Visa ganhar tempo e condições de se agir mais adequadamente em outro momento. Não é o mero calar-se ou fingir que não tá vendo ou ouvindo, mais a sabedoria para poder agir posteriormente de modo mais seguro. Ao "ignorarem" estes jovens estão dizendo que ultrapassam as expectativas alheias sobre uso de seus corpos e desejos, enquanto avançam para a compreensão de si mesmos como sujeitos empoderados dentro das relações de poder, possuidores de uma subjetividade e uma sexualidade legítimas que possibilita o desmantelamento da relação direta estabelecida entre discurso opressor e 
comportamento oprimido (homossexual). Recusa-se, assim, a deixar-se subjetivar por tais discursos, como vemos no relato a seguir

"Eu simplesmente apertei a tecla do foda-se e percebi que quanto menos eu me importava menos eles mexiam comigo. Agente sofre menos quando faz de conta que não é com a gente e segue vivendo. Porque acho que quando você não liga te machuca menos". (Sujeito 9).

Inviabilizar e/ou minimizar os efeitos das discriminações através do "ignorar" tende a representar nesse estudo a assunção da resistência como um movimento ativo de transformação da dinâmica do poder. No entanto, o "ignorar", embora pareça possuir um caráter mais reativo do que ativo, configurou-se, dentro do contexto da pesquisa, na estratégia mais utilizada pelos jovens entrevistados, o que nos faz pensar que seu uso, de fato, pode ser eficiente.

Entendo também que, por detrás da "tecla foda-se", ou seja, do "fazer pouco caso", do ignorar, estão acionados um conjunto de discursos sobre corpo e sexualidade - em grande parte trazidos de fora da escola - que dão sustentabilidade à decisão ética do sujeito de não se deixar abalar pelas agressões. Isso não significa que estes não se sintam incomodados com atitudes discriminatórias. O "ignorar" não pressupõe, necessariamente, ter "sangue de barata", mas, significa a capacidade de, em certas situações, fazer o adversário desperdiçar sua munição, como se atirasse contra o vento, num processo de invalidação do caráter subjetivador/deslegitimador que o discurso pejorativo poderia ter. No entanto, ao discorrer sobre tal estratégia podemos nos questionar: ao fazer uso do "ignorar" os jovens estão resistindo a quê?

Minha aposta inicial era a de que tais jovens empreendiam estratégias de resistência à homofobia presente na escola. Isso porque estava apegado ao conceito comumente difundido na literatura especializada que entende homofobia como qualquer sentimento e prática de aversão às homossexualidades (JUNQUEIRA, 2009; RIOS, 2008). Entretanto, ao realizar as entrevistas constatei algo bem interessante, que desestabilizou meu entendimento sobre homofobia na escola.

Enquanto esperava uma equivalência entre aquilo que a literatura dizia ser homofobia e o entendimento dos jovens sobre o que é homofobia na prática, fui pego de surpresa ao identificar nas falas dos mesmos, um descompasso referente ao entendimento do que configuraria uma prática homofóbica. Vejamos o que alguns participantes me disseram ao perguntar se as agressões que sofriam (chingamentos, piadas, "brincadeiras") eram casos de homofobia:

"Eles só foram ignorantes, nunca conviveram com alguém homossexual, tinham vários pré-conceitos, mas acho que era mais ignorância do que homofobia". (Sujeito 1).

"Isso é brincadeira de pessoas que não tem maturidade. Não acho que é Homofobia, mas também, não é brincadeira". (Sujeito 9). 
"Não era homofobia, nunca deixei chegar nesse nível. Acho que era só um preconceito que vinha de casa. Acho que homofobia é o preconceito quando atinge um nível "perigoso", que realmente afeta o próximo". (Sujeito 3).

"Se a homofobia servir para descrever o extremo do preconceito, onde o sujeito vê o outro como completamente insuportável, temos que reavaliar o que se designa por homofobia nos espaços escolares. Às vezes, esconjuramos qualquer fala por homofobia, qualquer gesto". (Sujeito 10).

Os relatos acima chamam nossa atenção para um fato importante. O descompasso existente entre a homofobia enquanto conceito sociopolítico e a homofobia enquanto prática de violência simbólica revela para nós que, no que tange a dar conta das realidades vivenciadas por estes jovens gays no contexto da escola de ensino médio, o conceito de homofobia, da forma como está consolidado hoje, se mostra insuficiente. O que queremos dizer com isso?

Quando o conceito tenta abarcar a violência simbólica é quando ele se frustra, por encontrar um universo de sujeitos praticantes muito amplo e bem mais difícil de precisar. Ao que parece, existe uma facilidade maior em dar conta dos aspectos jurídicos e físicos da questão. Entretanto, quando se trata do aspecto simbólico, talvez, ele deva vir acompanhado de outros conceitos, como o de heteronormatividade conforme já comentado por Rogério Diniz Junqueira (2012).

Assim, àquelas práticas normalmente nomeadas por nós como homofóbicas, foram significadas de outras formas pelos sujeitos da pesquisa. Seria o caso de dizer que tais jovens não assimilaram de forma satisfatória o conceito de homofobia? Ou mesmo dizer que esta falta de equivalência deve-se a banalização de tais práticas efetuadas pelos jovens?

Acredito que a questão vai além de identificar práticas e dizer se são ou não homofóbicas. O que me interessa mostrar aqui é que, parece existir uma dimensão da vivência homossexual que não pode ser explicada pelas vertentes sociológicas ou políticas, porque ela é relacional, ética, e não totalmente jurídica. Talvez, por isso, alguns dos jovens entrevistados não se reconheçam no conceito porque este não dá conta da dimensão subjetiva da vivência homossexual.

Isso talvez sinalize para nós que, problematizar a homofobia no espaço escolar vai além de caracterizar e diagnosticar os aspectos tangíveis da questão como, por exemplo, identificar e nomear práticas como homofóbicas, mas, inclui, principalmente, atentar para a relação ética e subjetiva que perpassam os processos de significação empreendidos por estes jovens. Assim, quando os jovens entrevistados dizem que não entendem como homofobia aquelas práticas que o conceito diz ser homofobia, eles estão dizendo, na realidade, que a tarefa de significar uma ação como homofóbica ou não, não cabe ao conceito, mas, é tarefa de cada indivíduo, baseado na forma como cada um vivencia sua sexualidade e constrói suas relações interpessoais dentro do jogo de poder. 
Como pesquisador, entendi que estava tentando conceber de forma demasiada a homofobia como uma violência simbólica. No entanto, como evidenciado nas falas, os participante resistiram a mim e, também, ao conceito. Isso me alertou para a constante necessidade de colocar em xeque àqueles conceitos que consideramos estáveis, evitando, assim, empreender numa espécie de patrulha ideológica, e, ressaltando os limites e potencialidades que cada conceito carrega.

Assim, acredito que as resistências produzidas no contexto desta pesquisa não foram direcionadas à homofobia nos moldes como a academia a conceituou. Existe uma questão que preocupa esses jovens e que não é dizer se algo foi ou não homofobia. O que mais parece interpelar esses sujeitos é a difícil tarefa de aprender a vivenciar uma sexualidade outra. A preocupação principal centra-se em como poderão performar uma sexualidade interditada. Neste respeito, as duas estratégias destacadas neste trabalho, apontam exatamente nesta direção. Ou seja, como empreender movimentos que permitam recusar o lugar de abjeção e possibilitem um maior empoderamento, a positivação da subjetividade homossexual e, como consequência, a evidenciação sem constrangimento da homossexualidade como comportamento legítimo.

\section{CONCLUSÃO}

A partir das entrevistas realizadas foi possível identificar estratégias que foram entendidas aqui como movimentos efetivos de resistências à lógica do poder deslegitimador das chamadas sexualidades embaraçosas. Cada uma delas desmantela de forma diferente o jogo de poder e objetivam possibilitar o empoderamento necessário para a vivência e evidenciação do comportamento homossexual como algo legítimo.

A primeira estratégia encontrada foi a do "deslocamento do discurso agressor". Com esta, subverte-se o discurso do agressor utilizando-o contra ele mesmo. O tiro, assim, sai pela culatra. Revertendo o potencial constrangedor do discurso contra o próprio agressor, evidencia-se um posicionamento ativo dentro da malha do poder por parte do jovem gay, bem como uma mudança na forma como a agressão é sentida.

Assim, foi possível perceber que o "deslocamento do discurso agressor" tem um duplo caráter, por um lado, evidencia uma vivência empoderada da sexualidade, e, por outro, denuncia a fragilidade do discurso agressor, mostrando que, a heterossexualidade pode ser tão vítima dos discursos deslegitimadores quanto à homossexualidade, e que isto pode ser feito revertendo a lógica da discriminação e questionando as bases que sustentam a heterossexualidade como único comportamento legítimo. 
Identifiquei, também, o "ignorar" como um segundo movimento de resistência empreendido pelos entrevistados. Desconsideram-se estrategicamente os efeitos subjetivadores negativos da agressão. Empreende-se, com isso, num movimento que, mais do que fazer vista grossa às chacotas e "brincadeiras", visa consolidar o entendimento de si como sujeito empoderado dentro das relações de poder, possuidor de uma subjetividade e uma sexualidade legítimas e, mais ainda, fazendo funcionar o processo de não reconhecimento do caráter subjetivador que o discurso pejorativo poderia ter. Além disso, evidencia uma tomada estratégica de decisão, adiando as ações reativas e ativas de resistências para uma situação mais propícia e segura.

A pesquisa revelou que, entender o "ignorar" como uma estratégia ativa de resistência, significa concebê-lo como uma forma de recusa ao lugar atribuído socialmente às homossexualidades. Significa, também, que o potencial que um discurso pode ter de interpelar corpos e subjetividades, neste caso, os discursos considerados homofóbicos direcionados ao corpo homossexual, depende do quanto o sujeito que dele é alvo tem positivado em si, no seu interior, a homossexualidade como um comportamento favorável.

Ao "ignorarem" o que estes jovens estão dizendo é que, mais importante do que dar atenção às expectativas alheias sobre como farão uso de seus corpos e desejos, é o entendimento de si como sujeito empoderado dentro das relações de poder, possuidores de uma sexualidade legítima.

O que a pesquisa também revela é que, ao produzirem enfrentamentos e resistências às práticas nomeadas homofóbicas na escola, os jovens pesquisados colocam em xeque os limites do conceito de homofobia, chamando nossa atenção para o caráter disperso e complexo que sua prática revela. Encontrei nos discursos dos jovens uma dimensão da prática homofóbica que escapa às discussões políticas e sociológicas atuais da homofobia, isso porque esta habitaria um campo relacional e ético do sujeito que não se limita ao conteúdo formal da homofobia (discriminação, violência, abusos, brincadeiras disfarçadas, etc.), pelo contrário, abre a perspectiva de que, na prática, há um movimento muito intenso e produtivo do sujeito - sempre em relação com as condições concretas da sociedade.

Mais do que a formalidade homofóbica parece que esses rapazes viveram na escola (ou em suas vidas em geral) a difícil tarefa de aprender a viver uma outra sexualidade, que também abarca a homofobia, mas, não se limita a ela. Evidencia-se, com isso, a necessidade de ponderar a força totalizadora do conceito de homofobia, indicando que ele é apenas mais um entre as lutas contra as sujeições, que os jovens de maneira (consciente ou não, politizada ou não) combatem. 


\section{REFERÊNCIAS}

ABRAMOVAY, Miriam; CASTRO, Mary Garcia. Juventude e Sexualidade. Brasília: UNESCO Brasil, 2004.

ACCETTO, Torquato. Da dissimulação honesta. Tradução de Edmir Missio. São Paulo: Martins Fontes, 2001

BAMPI, Lisete. Governo, subjetivação e Resistência em Michel Foucault. Revista Educação e Realidade. Janjjun. 2002.

BONTEMPO, D. E. Effects of at-school victimization and sexual orientation on lesbian, gay, or bisexual youths' health risk behavior. Journal of adolescent health, v. 30 , n. 5 , p. 364-374, 2002.

BORRILO, Daniel. Homofobia. Barcelona: Bellaterra, 2000.

BRITZMAN, Deborah P. O que é esta coisa chamada amor, identidade homossexual, educação e currículo. Educação e Realidade, UFRGS, v. 21, n. 1, 1996.

CASSAL, Luan Carpes; BICALHO, Pedro Paulo G. Homofobia e sexualidade: o medo como estratégia de biopoder. Revista de psicologia da Unesp, p. 57-64, 2011.

COSTA, Albertina de Oliveira; BRUSCHINI, Regina. Uma questão de gênero. Rio de Janeiro: rosa dos tempos. 1992.

DAVI, Edmar Henrique Dairell. Intolerância e homossexualidade: as marcas da homofobia na Cultura Ocidental. Caderno Espaço Feminino, Uberlândia, v. 13, n. 16, p. 119-137, jan./jun. 2005.

FÉLIZ DA SILVA, Jeane. "Quer teclar?": aprendizagens sobre juventudes e soropositividades através de bate-papos virtuais. Tese de Doutorado. Universidade Federal do Rio Grande do Sul- UFRGS. Faculdade de Educação. Porto Alegre: 2012.

FERRARI, Anderson. "Esses alunos desumanos": a construção das identidades homossexuais na escola. Educação e Realidade. Jan/jul,. p. 87-111, 2003.

FERRARI, Anderson. E quando as homossexualidades invadem a escola? In: MARQUES, Luciana Pacheco. (Re) Significando o outro. - Juiz de Fora: UFJF, 2008.

FERRARI, Anderson. Você já deve saber sobre minha "orientação sexual" (se não sabia, ficou sabendo agora, hehe) - subjetividades e sujeitos em negociação. In: FERRARI, Anderson. Sujeitos, subjetividades e educação. - Juiz de Fora: Editora UFJF, 2010. 
FLICK, Uwe. Introdução à pesquisa qualitativa. 3ำed. Porto Alegre: Artmed, 2009.

FOUCAULT, Michel. Ditos e Escritos II: Arqueologia das Ciências e História dos sistemas de pensamento. Rio de Janeiro: Forense Universitária, 2005.

FONTES, Malu. Ilustrações do silêncio e da negação. In: LIONÇO, Tatiana; DINIS, Débora. Homofobia e educação: um desafio ao silêncio. Brasília: Letras Livres: EDUNB, 2009.

GALÀN, José Ignacio Pichardo. Adolescentes ante La diversidad sexual: homofobia em los centros educativos. Catarata: Madrid, 2009.

HALBERSTAM, Judith Jack. Repensando sexo e gênero. In: MISKOLCI, Richard. Discursos fora da ordem: sexualidades, saberes e direitos. - São Paulo: Annablume; Fapesp, 2012.

JUNQUEIRA, R. O reconhecimento da diversidade sexual e a problematização da homofobia no contexto escolar. In: SEMINÁRIO CORPO, GÊNERO E SEXUALIDADE: discutindo práticas educativas, 2007, Rio Grande. Anais... Rio Grande, RS: Ed. da FURG, 2007.

JUNQUEIRA, Rogério Diniz (Org.). Diversidade Sexual na Educação: problematizações sobre a homofobia nas escolas. Brasília: Ministério da Educação, Secretaria de Educação Continuada, Alfabetização e Diversidade, UNESCO, 2009.

JUNQUEIRA, Rogério Diniz. Políticas de educação para a diversidade sexual: escola como lugar de direitos. In: LIONÇO, Tatiana; DINIZ, Débora. Homofobia \& Educação: um desafio ao silêncio. Brasília: Letras Livres: EdUnB, 2009.

JUNQUEIRA, Rogério Diniz. “A homofobia não é um problema. Aqui não há gays nem lésbicas!": Estratégias discursivas e estados de negação da discriminação por orientação sexual e identidade de gênero nas escolas. Revista de Psicologia da UNESP 9(1), 2010.

JUNQUEIRA, Rogério Diniz. Homofobia: limites e possibilidades de um conceito em meio a disputas. Natal: UFRN. Revista Bagoas. Vol. 1. n. 1, 2012.

JUNQUEIRA, Rogério Diniz. A gênese de uma categoria. Entrevista ao grupo CLAM +10 . 2017. Disponível em: http://clam.org.br/destaque/conteudo.asp?cod=12704 acesso em 29/10/2018 às 17:23.

LANASPA, Jesus Generelo. Lesbianas, gays, bisexuales o transexuales: adolescentes que no botan. In: Galàn, José Ignacio. Adolescentes ante La diversidad sexual: homofobia em los centros educativos. Catarata: Madrid, 2009. 
LIONÇO, Tatiana; DINIS, Débora. Homofobia e educação: um desafio ao silêncio. Brasília: Letras Livres: EDUNB, 2009.

LONGARAY, Deise Azevedo. "Eu já beijei um menino e não gostei, aí beijei uma menina e me senti bem": um estudo das narrativas de adolescentes sobre homofobia, diversidade sexual e de gênero. (Mestrado em educação): FURG, 2010.

LOPES, Denilson. Por uma nova invisibilidade. In: JUNQUEIRA, Rogério Diniz (org.). Diversidade Sexual na Educação: problematizações sobre a homofobia nas escolas. Brasília: Ministério da Educação, Secretaria de Educação Continuada, Alfabetização e Diversidade, UNESCO, 2009.

MACIEL JUNIOR, Auterives. Resistência e Prática de Si em Foucault. 2013. Disponível em: http://www.uva.br/trivium/edicoes/edicao-i-ano-vi/artigos-tematicos/artigo-tematico-1.pdf

NARDI, Henrique Caetano. Diversidade sexual, relações de gênero e políticas públicas. - Porto Alegre: Sulina, 2013.

PARAÍSO, Marlucy; SANCHES, Sabrina. Currículo, gênero e sexualidade: efeitos das eleições e políticas partidárias na escola. In: PARAISO, Marlucy Alves e SILVA, Maria Patrícia. (Orgs.). Pesquisas sobre Currículos e Culturas: tensões, movimentos e criações. Curitiba: Brazil Publishing, 2020 (NO PRELO).

PEREIRA, Henrique; LEAL, Isabel. A homofobia internalizada e os comportamentos para a saúde numa amostra de homens homossexuais. Revista Análise Psicológica, v. 1, 2002.

WEINBERG, G. Society and the healthy Homosexual. New York: St. Martin's, 1972. 